\title{
Characterization of Compression Strength of Granite-epoxy Composites Using Design of Experiments
}

\author{
Antonio Piratelli-Filho*, Frank Shimabukuro \\ Departamento de Engenharia Mecânica, Faculdade de Tecnologia, \\ Universidade de Brasília - UnB, 70910-900 Brasília - DF, Brazil
}

Received: November 11, 2007; Revised: October 29, 2008

\begin{abstract}
This paper presents a processing study of the polymer matrix composite (PMC) developed with an epoxy polymeric matrix reinforced with particulate ceramic granite. This PMC composite has been reported to be used as structural parts of machine tools and Coordinate Measuring Machines due to its superior vibration damping characteristics and reduced processing cycle over cast iron. The investigated processing variables were epoxy content and particle size and the mechanical characterization was carried out by compressive tests. Rejects of granite with particle size smaller than $500 \mu \mathrm{m}$ were prepared by crushing, milling and classification operations. The powder was mixed with different compositions of epoxy resin, between 15 and $20 \%$ in weight. An experiment was planned and executed according to the Factorial design technique using two variables at two levels. The obtained cylindrical samples were submitted to compressive strength tests and the results showed a maximum resistance of $114.23 \mathrm{MPa}$ at $20 \mathrm{wt}$. (\%) epoxy, value close to that of the literature.
\end{abstract}

Keywords: particulate composite, granite epoxy, machine structure

\section{Introduction}

A class of polymer matrix composites (PMC) having polymeric epoxy matrix and particulate granite has increasingly been used in substitution to traditionally used cast iron and aluminum alloys in machine structures. The advantages of these PMC are higher vibration damping (eight times of cast iron), higher thermal stability provided by reduced thermal expansion coefficient and superior geometric flexibility during fabrication provided by polymeric matrix. The drawbacks are associated to its low thermal conductivity in machines where intense heat is generated and that must be addressed during the machine design ${ }^{1}$.

This PMC material is being used to build precision machine parts aiming at reducing errors associated to vibrations during operation ${ }^{1}$. An application in microscope support fabrication using granite-epoxy composite was reported by literature ${ }^{2,3}$. Some authors recently related the potential of these composites for the development of precision machine structures ${ }^{4,5,6}$.

The potential of this PMC class resulted in some commercial patents registered by manufacturers. The Swiss manufacturer Fritz Studer patented Granitan and it is considered as a pioneer in the development of machine structures based on granite-epoxy composites. Studer had observed that the lower rigidity with respect to cast iron may be compensated by increasing the thickness of the designed parts ${ }^{1}$. American ITW Philadelphia Resins Polymer Casting Division developed Zanite, a composite with epoxy and 91-93\% weight of granite. Anocast (EUA) developed an epoxy-quartz composite and Hardinge developed Harcrete with epoxy and 93\% weight of granite. German ElbShliff Werkzeugmachinen developed Microgranit with epoxy and granite.

Mason ${ }^{1}$ pointed out that Romi manufacturer had been producing in Brazil a model of machine tool with structure in granite-epoxy composite. Mendonça et al. ${ }^{7}$ presented a research work that was carried out to obtain a similar material using granite and epoxy and the results showed a compressive strength resistance of $90 \mathrm{MPa}$ when using $15 \%$ in weight of epoxy. This strength value was still reduced when compared to some commercial brands (about $137 \mathrm{MPa}$ ), but improvement in resistance could be attained by controlling the processing variables. Recent developments were presented by Campos Rubio et al. $^{8}$ and Panzera and Campos Rubio 9 . These authors reported the processing and properties of particulate composites using particulate silica ceramic mixed with epoxy polymeric resin.

The compressive strength is being considered as a reference property for structural applications as designed parts have their dimensions defined according to the known material strength. The improvement in the compressive strength and the understanding of its relationship with the processing variables may be accomplished by applying statistical techniques as design of experiments (DOE). The DOE statistical techniques have a long history as the first work was reported by Sir Ronald Fisher in the 1920s applied to agriculture ${ }^{10}$. Some of the first developed DOE techniques were the random blocks, the Latin squares, the Greco-latin squares and the Hyper-greco-latin squares, limited to investigating a small number of variables.

Another DOE was introduced aimed at increasing the number of variables to all possible level combinations, called Factorial design. This DOE has the advantage of investigating the interactions among the involved variables, but it requires a large number of experimental trials (runs) as the number of variables increase. The interactions may be investigated with only a fraction of the total number of runs by using the Fractional Factorial design. Its construction is done by fractioning the Factorial design using some high order interactions as a basis. New reported developments were the Mixture designs and Response surface designs, devoted to defining a mathematical model applicable to the problem under investigation ${ }^{11}$.

In the last decade, an increasing interest in DOE techniques was observed and its application in industry was introduced as a tool for quality improvement and costs reduction. The popularization of these techniques is associated to the Japanese engineer Genichi Taguchi. He introduced the so called Taguchi methods in the industrial environment, based on highly fractionated Factorial designs ${ }^{10}$. 
The selection of an experimental design involves a detailed study of the process aiming at finding the variables affecting the properties. Montgomery ${ }^{10}$ pointed out that the first step is the selection of these variables and their values or levels. The results, referred as the response variable, may be written as a function of these process variables (referred as independent variables) and an experimental plan is selected depending on the amount of runs required for a given accuracy. The most known way of experimentation is the one-factorat-a-time variation, i.e., the effect of one variable is investigated considering all the others as constant. A problem that may arise from this experimentation technique is that the interaction between two or more variables is not predicted as there is not investigation of the effect of changing two or more variables simultaneously ${ }^{12}$.

The main advantage of the Factorial design is the possibility of verifying a great number of variables and interactions among them. The number of total experimental essays or runs $(\mathrm{N})$ is determined by the relation $\mathrm{N}=\mathrm{m}^{\mathrm{k}}$, where $\mathrm{m}$ is the number of levels of each variable under investigation and $\mathrm{k}$ is the number of variables under investigation. The simplest designs have two or three levels at each variable and the number of runs $\mathrm{N}$ is determined by the relations $\mathrm{N}=2^{\mathrm{k}}$ and $\mathrm{N}=3^{\mathrm{k}}$, respectively.

This work presents a processing study of PMC structural composites based on granite powder and epoxy polymeric resin. The Factorial design technique was used to study the effect of two processing variables, granite granulation and epoxy content and its interaction. A selected range of variation of these variables was studied to improve the compressive resistance.

\section{Experimental Procedure}

\subsection{Materials}

The particulate composite was obtained with granite powder mixed with an epoxy polymeric resin. Granite's composition shows feldspars and quartz minerals and the particle granulation is generally greater than $5 \mathrm{~mm}$. According to Ashby \& Jones ${ }^{13}$, granite has a density of $2.6 \mathrm{Mg} / \mathrm{m}^{3}$, a Young Modulus of 60 to $80 \mathrm{GPa}$, a tensile strength of $23 \mathrm{MPa}$ and a compressive strength of 65 to $150 \mathrm{MPa}$.

An epoxy resin YD-128 from Ipiranga Comercial Química was used to process the samples. This resin is a Bisphenol A based and its cure was accomplished by adding Ancamide 805 curing agent. The properties of this epoxy resin after the cure are a density of $1.17 \mathrm{Mg} / \mathrm{m}^{3}\left(20^{\circ} \mathrm{C}\right)^{14}$, a tensile strength of $61 \mathrm{MPa}$ and a compressive strength of $83 \mathrm{MPa}^{15}$.

\subsection{Sample preparation and experiment design}

The materials were processed beginning by crushing of the granite plates. Rejects of black granite were fragmented in a Mundibra crushing machine and milled in a Siebtechnik milling machine. The milling machine has a cylindrical container in cast iron with two smaller cylinders inside. The machines were cleaned with alcohol and the granite plates were inserted into the crushing machine in parts of nearly 3 to $4 \mathrm{~kg}$. The fragmented granite was then inserted into the milling machine container in amounts between 0.1 and $0.15 \mathrm{~kg}$. The obtained granite powder was classified in classes of granulation using sieves in brass and aluminum with $500 \mu \mathrm{m}, 106 \mu \mathrm{m}$ and $45 \mu \mathrm{m}$ mesh.

As an attempt of fulfilling the porosity when dealing with only one particle dimension, it was decided to work by combining two classes of particles, big and small particles mixed together with the small ones fulfilling the spaces among the big ones. The following weight balance was used: i) $50 \%$ of particles with dimension between 106 and $45 \mu \mathrm{m}$ added to $50 \%$ of particles with dimension between
$106 \mu \mathrm{m}$ and $500 \mu \mathrm{m}$ (MIX 50-50); ii) $70 \%$ of particles with dimension between $106 \mu \mathrm{m}$ and $45 \mu \mathrm{m}$ and $30 \%$ of particles with dimension between $106 \mu \mathrm{m}$ and $500 \mu \mathrm{m}$ (MIX 70-30). The magnitude of the particle granulation and correspondent sieves were selected as small samples were under preparation, but this may be changed when dealing with large parts.

The Epoxy resin was prepared by mixing $60 \mathrm{phr}$ (parts per hundred parts of resin) of curing agent Ancamide 805 to the liquid resin YD-128, giving a gel time of 1 hour and 5 minutes. During this time span, the composite samples were prepared by mixing the granite powder and the epoxy. The Epoxy content was controlled at 15-20\% in weight, as suggested by a previous work showing a decrease in resistance when the epoxy content increases? ${ }^{7}$.

Two variables were under investigation to understand its effect over compressive strength of the composite and thus optimize the resistance. The most known option is the use of the one-factor-at-a-time experimentation, but it results in lost information on the interaction between the variables. The experiment design techniques of factorial design were then used to combine the two variables in two values or levels and it was selected the $2^{2}$ factorial design.

The experimental plan of the Factorial design may be summarized by standard tables called experimental arrays. The array shows the variables represented by capital letters at each column and the variable levels represented by numbers -1 and +1 . Each line in the array represents the runs or tests that are combinations of the variables' level. Table 1 shows the experimental array of the factorial design $2^{2}$, where $\mathrm{A}$ and $\mathrm{B}$ are the variables under investigation, $\mathrm{AB}$ is the interaction between $\mathrm{A}$ and $\mathrm{B}$, the values -1 and +1 represent the lower and upper values (levels) of each variable and interaction. For instance, the run number one must be carried out with variable $\mathrm{A}$ at level -1 (lower) and variable B at level -1 (lower). The runs must be executed in random sequence, in order to avoid any bias in the results. Replication is recommended to obtain more representative results before performing analysis.

The mathematical model of the factorial design $2^{2}$ is presented in Equation 1. The response variable (for instance, the compressive strength) is a function of the variables $\mathrm{A}$ and $\mathrm{B}$ and its interaction AB. The Greek letters $\tau$ and $\beta$ represent the effects of the variables $A$ and $B$ at levels $i$ and $j$ over the response variable $y$, the variation in compressive strength relative to the mean of all results of the experiment $(\mu)$. The letter $\varepsilon$ represents the residual error at each 1 replicated observation (measured y value). If required, the parameters of this model may be determined by regression analysis techniques fitting a least squares equation over the experimental results ${ }^{13}$.

$$
y_{i j l}=\mu+\tau_{i}+\beta_{j}+(\tau \beta)_{i j}+\varepsilon_{i j l}
$$

Samples of cylindrical geometry were prepared to carry out compressive strength tests. A matrix of polymeric Poly (vinyl-chloride) (PVC) was used. The internal surfaces of the matrix were accurately prepared by cleaning, covering with a Tec Glazer wax and polishing. The height-diameter ratio of the samples was settled in 2.0.

The samples were prepared according to the Factorial design $2^{2}$ showed in Table 1, with variables A and B and levels -1 and +1 . The

Table 1. Experimental array of Factorial design $2^{2}$

\begin{tabular}{cccc}
\hline Run & A & B & AB \\
\hline 1 & -1 & -1 & +1 \\
2 & -1 & +1 & -1 \\
3 & +1 & -1 & -1 \\
4 & +1 & +1 & +1 \\
\hline
\end{tabular}


levels of the variables epoxy content (A) and granite granulation combination (B) used to prepare the samples are presented in Table 2. As showed, the epoxy content (A) of $15 \%$ weight is equivalent to the level -1 and $20 \%$ weight is equivalent to the level +1 . The variable granite granulation (B) was represented by the levels MIX 50-50 $(-1)$ and MIX 70-30 (+1).

The epoxy-granite slurries were introduced onto the cylindrical cavity of the matrices, where they remained for 48 hours. After that, the samples were extracted from the matrices and should wait seven days to complete the cure. The cure process was accelerated by heating the samples in an electric furnace at $60{ }^{\circ} \mathrm{C}$ during 4 hours. There were obtained 12 samples according to the Factorial design as 3 replicates of each run were prepared.

\subsection{Compressive tests and statistical analysis}

Compressive tests were carried out using a Universal testing machine, establishing the loading rate of $153 \mathrm{~N} / \mathrm{s}$. The samples were increasingly stressed until they failed at the maximum compressive stress applied. The compressive strength was then registered to perform the analysis of the results. The calculations were performed using the MatLab software.

A residual analysis was first performed to verify the assumption of normality of the results by plotting the observed and the expected cumulative residuals probability. The analysis of variance (ANOVA) was carried out to determine the most statistically significant variables affecting the results according to Fisher F Test applied over variance estimates ${ }^{10,12}$.

The estimative of the variances were determined by the sum of squares (SS) associated to the variable divided by the respective degrees of freedom (DF) and named mean squares (MS). Each sum of squares (SS) was determined according to Equation 2. In this equation, the value $r$ is the number of repetitions of each experimental run. The number of degrees of freedom of each effect was determined by the number of levels minus 1 , as the effect at each variable represents the variation of the results in relation to the mean.

$$
S S_{i}=\frac{Z_{i}^{2}}{r \cdot \sum_{j=1}^{N} c_{j}^{2}}
$$

Table 2. Variables and levels adopted in Factorial design $2^{2}$.

\begin{tabular}{ccc}
\hline Variables & \multicolumn{2}{c}{ Levels } \\
\cline { 2 - 3 } & -1 & +1 \\
\hline A Epoxy content (\%) & 15 & 20 \\
B Granite granulation & MIX 50-50 & MIX 70-30 \\
\hline
\end{tabular}

The amount $Z_{i}$ is defined by Equation 3 when two-level variables are investigated. These $Z_{i}$ are linear combinations of the terms $T_{1}$, $\ldots, \mathrm{T}_{\mathrm{N}}$ having coefficients $\mathrm{c}_{1}, \ldots, \mathrm{c}_{\mathrm{N}}$ and represents the effect of each variable. In this expression, the coefficients $c_{1}, \ldots, c_{N}$ are the variable levels defined by signal -1 or +1 and the terms $T_{1}, \ldots, T_{N}$ are the totals determined by the sum of the determined values at each experimental run.

$$
Z_{i}=c_{1} \cdot T_{1}+c_{2} \cdot T_{2}+\ldots+c_{N} \cdot T_{N}
$$

The total sum of squares (SST) was determined by Equation 4 , corresponding to the squared difference between each determined result $\left(\mathrm{y}_{\mathrm{ij}}\right)$ and the global mean of all results $(\overline{\bar{y}})$. The residual sum of squares (SSR) was determined by the difference between the SST and the sum of squares of all variables and interactions $(\mathrm{SSR}=$ SST-SSA-SSB-SSAB).

$$
S S T=\sum_{i=1}^{N} \sum_{j=1}^{r}\left(y_{i j}-\overline{\bar{y}}\right)^{2}=\sum_{i=1}^{N \cdot r} y_{i}^{2}-\frac{\left(\sum_{i=1}^{N \cdot r} y_{i}\right)^{2}}{N \cdot r}
$$

The mean squares (MS) associated to the variables, interactions and residuals were determined as to apply the F Test. Table 3 summarizes the ANOVA calculations applied to the factorial design $2^{2}$, with two variables at two levels. The $\mathrm{F}$ test was carried out by taking the residual sum of squares (MSR) as a reference, dividing each variable and the interaction mean square (MS) by MSR and determining the $\mathrm{F}$ value that must be compared with the $\mathrm{F}$ distribution to verify its statistical significance (probability) ${ }^{10}$.

\subsection{Microstructure characterization}

In order to better understand the ANOVA results, a microstructure analysis was carried out. The samples were prepared by sanding the surfaces with 180, 220, 400, 600 and 1200 mesh sandpaper and polishing with alumina $0.3 \mu \mathrm{m}$. The surfaces were examined using an optical microscope Nikon Optiphot with a system for capturing images. The photomicrographs were obtained with amplifications of 50 and $100 x$ and the files were stored in the computer attached. The characteristics and phases of the surfaces were observed and reported.

\section{Results and Discussion}

The samples presented a good structural integrity and regular cylindrical shapes. Compression strength results of the granite-epoxy samples are presented in the Table 4. The maximum compression strength was observed for this composition and the observed value was 114.23 MPa. This result may be compared with those of some

\begin{tabular}{|c|c|c|c|c|}
\hline Source of variation & SS & DF & MS & $\mathrm{F}$ \\
\hline A & SSA & DFA & $\mathrm{MSA}=\mathrm{SSA} / \mathrm{DFA}$ & $\mathrm{F}_{\mathrm{A}}=\mathrm{MSA} / \mathrm{MSR}$ \\
\hline $\mathrm{B}$ & SSB & DFB & $\mathrm{MSB}=\mathrm{SSB} / \mathrm{DFB}$ & $\mathrm{F}_{\mathrm{B}}=\mathrm{MSB} / \mathrm{MSR}$ \\
\hline $\mathrm{AB}$ & SSAB & DFAB & $\mathrm{MSAB}=\mathrm{SSAB} / \mathrm{DFAB}$ & $\mathrm{F}_{\mathrm{AB}}=\mathrm{MSAB} / \mathrm{MSR}$ \\
\hline Residual & SSR & DFR & $\mathrm{MSR}=\mathrm{SSR} / \mathrm{DFR}$ & - \\
\hline Total & SST & DFT & - & - \\
\hline
\end{tabular}
manufacturers that produce similar material, being better than the

Table 3. ANOVA of the Factorial design $2^{2}$. 
Table 4. Results of compressive strength.

\begin{tabular}{ccc}
\hline Epoxy $(\%)$ & Granite granulation & $\sigma_{\max }(\mathrm{MPa})$ \\
\hline 15 & MIX 50_50 & 106.48 \\
15 & MIX50_50 & 100.20 \\
15 & MIX 50_50 & 94.51 \\
15 & MIX 70_30 & 103.00 \\
15 & MIX 70_30 & 109.49 \\
15 & MIX 70_30 & 87.51 \\
20 & MIX 50_50 & 114.23 \\
20 & MIX 50_50 & 108.34 \\
20 & MIX 50_50 & 105.26 \\
20 & MIX 70_30 & 107.95 \\
20 & MIX 70_30 & 106.09 \\
20 & MIX 70_30 & 103.73 \\
\hline
\end{tabular}

one of Hardinge's Harcrete ${ }^{1}$ (107.6 MPa), close to the Anocast's $\operatorname{Anorad}^{16}(110-117 \mathrm{MPa})$ and smaller than that of Zanite ${ }^{17}(137 \mathrm{MPa})$, as observed in Figure 1. Zanite reports that its composite material is made of quartz instead of granite and presents a proportion of 7-9\% in weight of epoxy.

As showed in Table 4, the dispersion of the results embarrass the identification of the variables effects, the epoxy content and granite granulation, as the standard deviation is larger than the variation in mean results.

A statistical analysis was carried out and the first step was the verification of the suitability of the results building the normal probability plot of the compression strength data. This analysis is presented in Figure 2 and it shows that the results have a distribution close to the normal ones, as data of observed and expected cumulative probability are distributed along a straight line. The data are suitable to carry out the analysis of variance (ANOVA).

The ANOVA results are presented in Table 5. These results indicate that epoxy content (variable A) was statistically significant at the probability of $90.1 \%$, according to the F test applied. It is interesting to observe that the level of epoxy content with $20 \%$ proved to produce a bigger compressive strength than with $15 \%$ in weight of epoxy, different from expected. It should be considered that previous results ${ }^{7}$ showed epoxy content greater than $25 \%$ in weight, producing compressive strength smaller than that with $20 \%$ epoxy. It was observed that the samples with $15 \%$ in weight of epoxy presented some difficulties during the processing step, as a small amount of epoxy was manually mixed with granite powder. In order to reduce the epoxy content and improve the resistance, the detected bias could be changed by using vibration machines to mix the components and to promote the resin cure under pressure in a closed matrix.

The studied granite granulation (variable B) did not appear to produce significant effect on the compressive resistance, as the $\mathrm{F}$ test indicates a large probability $(36.11 \%)$. The same applies to the interaction $\mathrm{AB}$ between the epoxy content and the granite granulation, with probability of $28.11 \%$.

The interaction effect is shown in Figure 3. As observed, there is small difference in compressive strength when the levels of the variables are changed simultaneously, e.g., when changing of epoxy$15 \%$ to epoxy-20\% there is an increase in compressive strength if the granite granulation changes, but the difference is not equal to the one observed at $15 \%$ epoxy. The non-parallel lines indicate interaction possibility, but as observed with the test F in ANOVA, this interaction is not statistically significant.
Table 5. Analysis of variance (ANOVA) results.

\begin{tabular}{lrrrc}
\hline $\begin{array}{l}\text { Source of } \\
\text { variation }\end{array}$ & SS & DF & MS & $\begin{array}{c}\text { F } \\
\text { (probab. }>\text { F) }\end{array}$ \\
\hline A & 164.354 & 1 & 164.354 & $3.49(0.099)$ \\
B & 10.547 & 1 & 10.547 & $0.22(0.6489)$ \\
AB & 6.556 & 1 & 6.556 & $0.14(0.7189)$ \\
Residual & 377.251 & 8 & 47.156 & - \\
Total & 558.708 & 11 & - & - \\
\hline
\end{tabular}

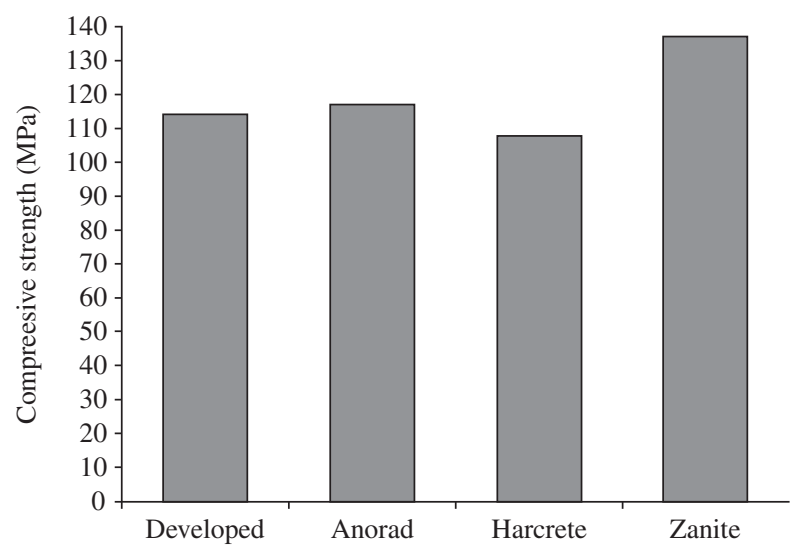

Figure 1. Compressive strength comparative values of some granite-epoxy composites.

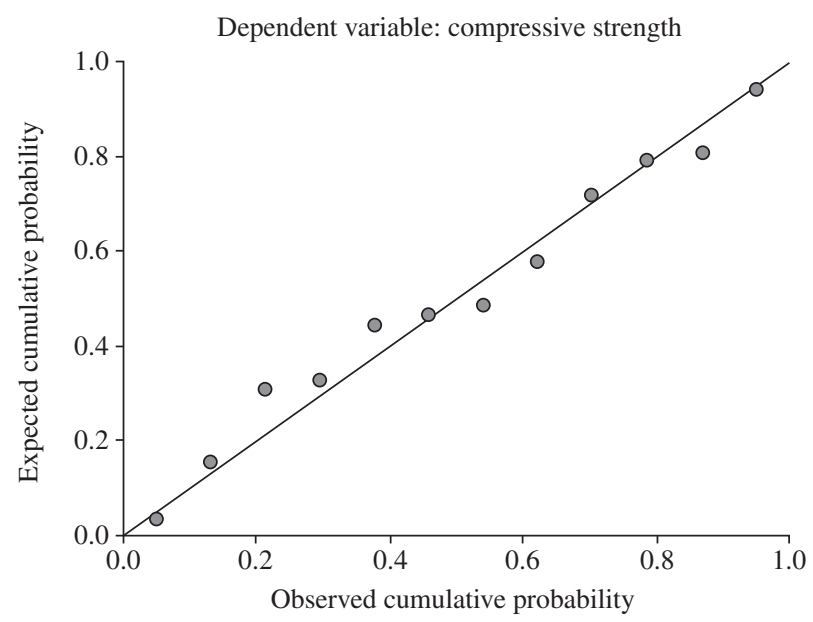

Figure 2. Normal probability plot of the compressive strength.

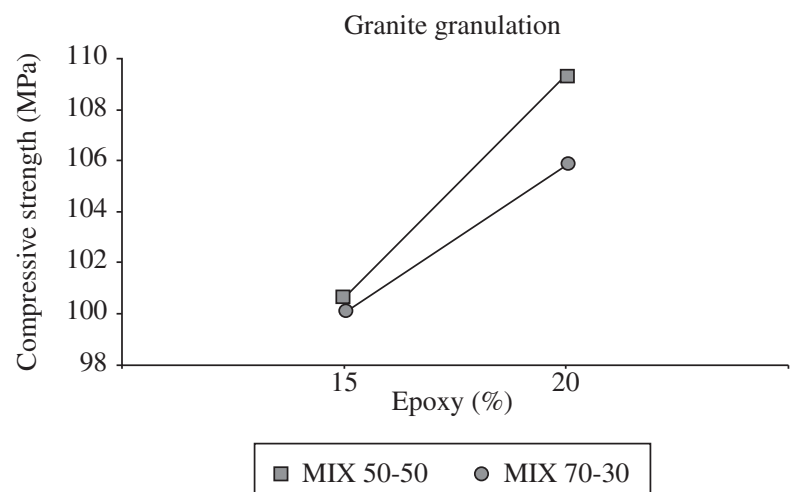

Figure 3. Mean effects of variables $\mathrm{A}$ and $\mathrm{B}$ and $\mathrm{AB}$ interaction. 
The analysis of the microstructure is presented in Figure 4. This figure shows two different samples having $15 \%$ in weight of epoxy (a and b) and 20\% in weight of epoxy (c), with the same proportion of particles (50-50). Two different phases were observed, granite (clear) and epoxy (dark). It was observed clusters of granite particles

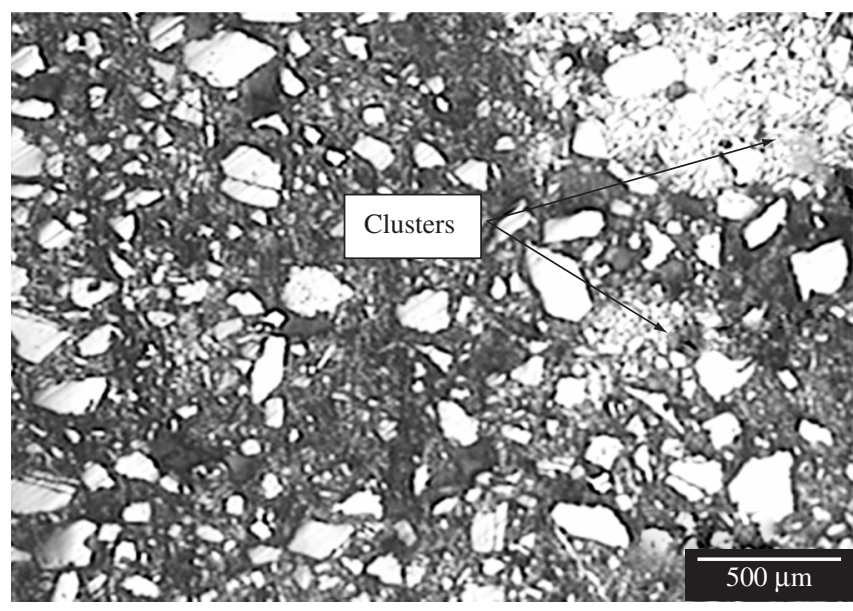

(a)

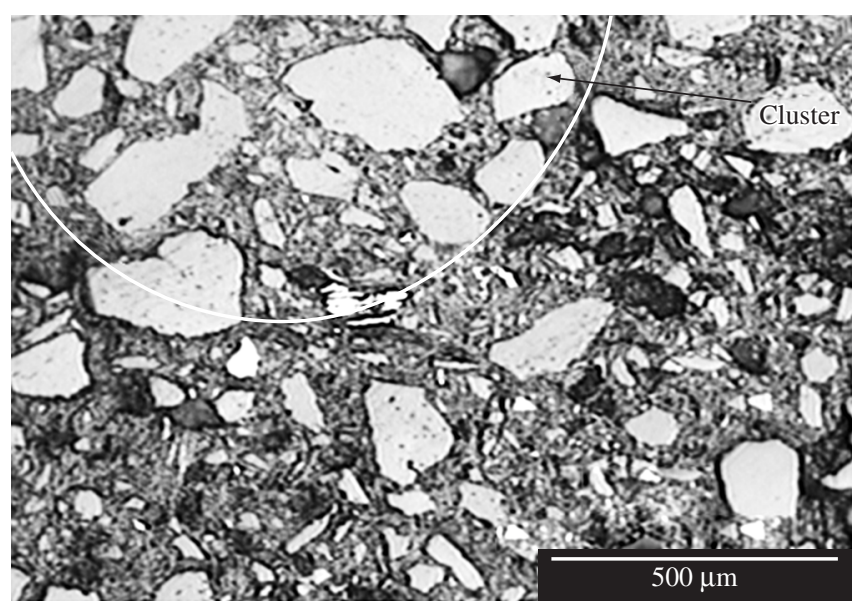

(b)

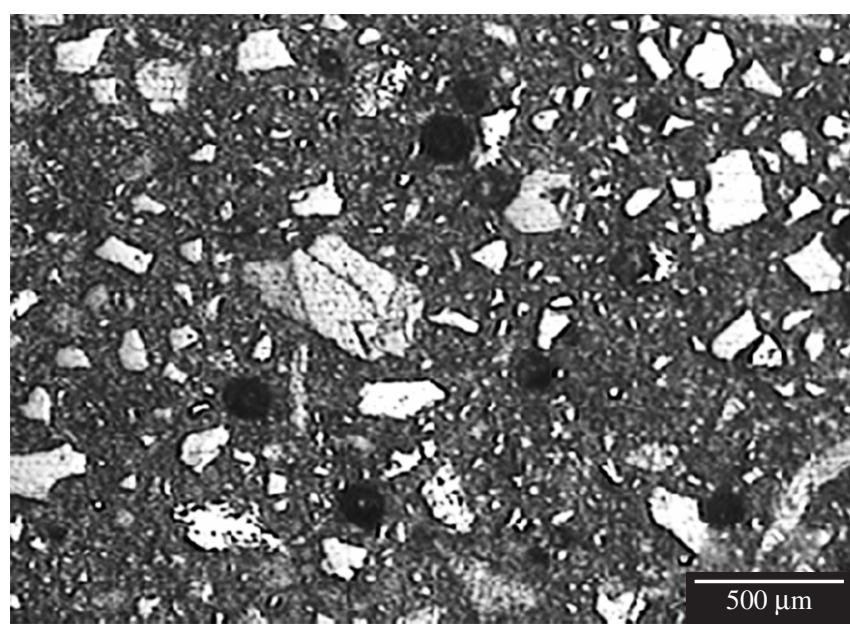

(c)

Figure 4. PMC microstructure with 50-50 granite particles ratio and different weight compositions and amplifications: a) $15 \%$ epoxy, 50x; b) $15 \%$ epoxy, 100x; and c) 20\% epoxy, 50x. distributed in the microstructure of samples with $15 \%$ in weight of epoxy, showed in Figure 4a, and showed in detail in Figure $4 b$. The presence of clusters may be associated with the reduction in resistance as the adhesive bonds among granite particles promoted by epoxy are irregular or inexistent in the cluster regions. It was observed that samples with $20 \%$ in weight of epoxy presented some areas with porosity in the microstructure, as shown in Figure 4c. This porosity may be associated to the fabrication process as they have a characteristic rounded format. The larger size of the clusters in relation to the pores presented in samples with 15 and $20 \%$ in weight of epoxy, respectively, may explain the reduced compressive strength of samples with $15 \%$ when compared with $20 \%$. An attempt to increase the compressive strength shall deal with reduction of clusters and porosity.

\section{Conclusion}

The influence of epoxy content between 15 and 20\% in weight and two granite granulation over compression strength of the PMC was investigated. It was observed that the largest compression strength was 114.23 MPa and it was determined with $20 \%$ in weight of epoxy and with the combination of granite particles rate of $50 \%$ small and $50 \%$ large (MIX 50-50). These results showed slightly superior magnitude with respect to similar commercial brands as Harcrete (with $93 \%$ granite and compressive strength $\sigma_{c}=107.6 \mathrm{MPa}$ ) and similar results when compared to Anocast (with quartz and compressive strength $\sigma_{\mathrm{c}}=110$ to $117 \mathrm{MPa}$ ), but it was reduced when compared to Zanite (with 7 to $9 \%$ weight epoxy and a compressive resistance $\left.\sigma_{c}=137 \mathrm{MPa}\right)$.

Factorial design was suitable to perform the investigation. ANOVA results showed that epoxy content was statistically significant (90\% probability) to explain the observed compressive strength variation. Granite granulation and the interaction between granite granulation and epoxy content did not produced statistically significant variation in the data. It must be observed that the reduction of the epoxy content should produce an increase in resistance, but what was determined was a counter effect. This was associated to the difficulties in the composite preparation and the associated clusters observed in microstructure. The use of an industrial processing method could reduce the magnitude and amount of clusters and pores in microstructure and then improve the resistance.

Future developments may deal with improvements in the processing steps and with substitution of the particulate ceramic material to increase the composite's compressive strength. Studies concerning vibration damping and prototypes manufacturing of this composite material are also proposed.

The authors acknowledge the Coordenação para Aperfeiçoamento de Pessoal de Nível Superior (Capes, Brazil) by the financial support that made this work concluded.

\section{References}

1. Mason F. Bases de máquinas de polímeros fundidos. Revista Máquinas e Metais. 2001; 4:64-83.

2. Ribeiro FMM, Purquério BM. Granito sintético para estruturas de equipamentos de precisão de pequeno porte - metodologia de projeto. In Proceedings of the $15^{\text {th }}$ Congresso Brasileiro de Engenharia Mecânica - COBEM; 1999, November 22-26; Águas de Lindóia, SP, Brazil.

3. Purquério BM, Mendonça FRM. Synthetic granite for precision equipment: conception, analysis and processing. Key Engineering Materials. 2001; 189:73-78.

4. Ohama Y. Recent progress in concrete-polymer composites. Advanced Cement Based Materials. 1997; 5(2):31-40. 
5. Fowler DW. Polymers in concrete: a vision for the 21 st century. Cement \& Concrete Composites. 1999; 21(5):449-452.

6. Orak S. Investigation of vibration damping on polymer concrete with polyester resin. Cement and Concrete Research. 2000; 30(2):171-174.

7. Mendonça RML, Piratelli-Filho A, Levi-Neto F. Compósitos Particulados para aplicações em engenharia de precisão: obtenção e propriedades mecânicas. In Proceedings of 2nd COBEF; 2003, May 18-21; Uberlândia, MG, Brazil.

8. Campos-Rubio J, Panzera TH, Silva DM, Vilela JJ. Como obter o melhor compósito para construção de estruturas de máquinas de pequeno porte. Plástico Industrial. 2006; 9:104-115.

9. Panzera TH, Campos-Rubio J. Development of a Polymeric Particulate Composite for Precision Engineering Applications. CIRP Journal of Manufacturing Systems. 2006; 35:12.

10. Montgomery DC. Design and analysis of experiments. New York: JohnWiley \& Sons; 1991.
11. Steinberg DM, Hunter WG. Experimental Design: Review and Comments. Technometrics. 1984; 26(2):71-97.

12. Box GEP, Hunter WG, Hunter JS. Statistics for experimenters. New York: John Wiley \& Sons; 1978.

13. Ashby MF, Jones DRH. Engineering Materials. New York: John Wiley \& Sons; 1988.

14. Epoxy Bisphenol-A YD-128 Catalog. [cited 2008, September 8]. Available from: http://www.kukdo.com/file/goods/YD-128_TDS_1.pdf.

15. Ancamide 805 catalog. [cited 2008, May 16]. Available from: http://www. gmzinc.com/uploads/docs/TD_Ancamide_805.pdf.

16. Anorad, Rockwell Automation catalog. [cited 2008, June 9]. Available from: http://pdf.directindustry.com/pdf/anorad/general-catalog/117635592-_149.html.

17. Zanite polymer composite, ITW Polymer Castings catalog. [cited 2008, June 9]. Available from: http://www.zanite.com/properties.html. 